\title{
Comunicación

\section{Bibliografías, biblionomías, bibliometrías: los libros fundamentales en el estudio de la comunicación}

RAÚL FUENTES NAVARRO ${ }^{1}$

Como parte de un proyecto de investigación en proceso sobre la constitución científica del campo académico de la comunicación, se revisan en este artículo algunos acercamientos, nacionales y extranjeros, de diverso tipo y alcance, sobre la bibliografia considerada como fundamental en (y para) los estudios de la comunicación, algunos de ellos descriptivos ("bibliometrías") y otros más bien normativos ("biblionomías"). Se exponen, desde ese marco, avances de resultados empíricos obtenidos de las tesis de maestría en comunicación presentadas entre 1996 y 2005 en cinco universidades mexicanas.

PALABRAS CLAVE: campo académico de la comunicación, tesis de posgrado, análisis descriptivo, bibliografía, bibliometría.
In the context of an ongoing research project concerning the scientific constitution of the field of communication studies, this article reviews some national and international approaches on the bibliography presented as foundational, from a diversity of standing points, for this kind of studies. These approaches include both descriptive ("bibliometries") and rather normative ("biblionomies") perspectives, and serve as a framework for the exploration of empirical data extracted from master's degree theses presented at five mexican universities between 1996 and 2005.

KEY WORDS: academic field of communication, theses and dissertations, descriptive análisis, bibliography, bibliometrics.

1 Instituto Tecnológico y de Estudios Superiores de Occidente.

Correo electrónico: raul@iteso.mx 
En la mayor parte de los ambientes universitarios, la relación entre programas educativos y fuentes bibliográficas parece evidente: en los libros se encuentran sistematizados los saberes que los estudiantes deberán apropiar y, quizá, "aplicar" en el ejercicio de una profesión, en la práctica de la investigación, en su ubicación "ilustrada" y eficaz en el entorno social. Evidentemente también, ese supuesto ha sido extensamente cuestionado, problematizado y, en el extremo, negado. Pero es sin duda un aspecto central de la realidad académica, que en el contexto de los debates sobre la "sociedad de la información" o "del conocimiento", manifiesta claramente su alta complejidad y pertinencia para la discusión.

En el campo de estudios de la comunicación esta relación problemática y compleja entre programas educativos y fuentes bibliográficas no sólo ha estado presente en todas las fases de su historia, en todas partes, sino que por las características mismas de su constitución como especialidad académica multidisciplinaria, sigue siendo un objeto de análisis al mismo tiempo poco conocido empíricamente y sujeto, no obstante, al ejercicio de múltiples condicionamientos sobre "lo que debe ser". La pregunta sobre "los libros fundamentales en (y para) el estudio académico de la comunicación", y su obligada asociación con la "teoría de la comunicación", admite diversos tipos de respuestas: algunas descriptivas, otras normativas; pero ninguna de ellas parece ser no digamos "definitiva", sino al menos local y provisionalmente satisfactoria.

En este artículo se revisan algunos acercamientos, nacionales y extranjeros, de diverso tipo y alcance, al abordaje de esa pregunta y al ofrecimiento de respuestas, algunas descriptivas ("bibliometrías") y otras más bien normativas ("biblionomías"), sobre la bibliografía ("Lista de libros sobre cierta materia, o información acerca de ellos", Moliner, 1992: 373) considerada como fundamental en (y para) los estudios de la comunicación. La indagación forma parte del proyecto de investigación La constitución científica del campo académico de la comunicación en México y en Brasil: análisis comparativo, realizado por quien escribe el presente artículo y con apoyo del Fondo de Ciencia Básica del CONACyT $(47377$ H). 


\section{TEORÍAS DE LA COMUNICACIÓN,}

\section{LIBROS DE TEXTO Y TEXTOS CANÓNICOS}

En un libro profundamente autorreflexivo (y "posmoderno", según su autor), publicado en 1996, el profesor estadounidense James A. Anderson propone un marco de análisis ontológico, epistemológico, praxeológico y axiológico desde el cual traza un modelo de intersecciones entre las "comunidades disciplinarias" de la comunicación y sus "genealogías teóricas" con los "campos de escolaridad" (scholarship)2. Para revisar las características de las "teorías de la comunicación", recurre al espacio social donde estas pueden ser significativas, es decir, los procesos de formación universitaria de "especialistas" en comunicación.

Cuando examinamos las prácticas ordinarias de la educación profesional y de posgrado, vemos que la mayoría de nosotros entramos al estudio de la teoría mediante una jerarquía común de eventos. Típicamente, comenzamos con dos rutas curriculares llamadas "teoría" y "método". Primero entramos en la teoría a través de descripciones normalizadas, en libros de texto, de marcos teóricos generalizados, casi siempre dentro de alguna división tópica (comunicación organizacional, periodismo, etc.). Probablemente aprendimos esos marcos por sus "ismos" (cognitivismo, conductismo, funcionalismo, estructuralismo, interaccionismo, etc.), si es que llegamos a la teoría a través de la ciencia. Lo que nos fue proporcionado, sin embargo, depende de cuándo y dónde nos fue enseñado. Hay demasiado que ofrecer en cualquier momento y lugar dados.

2 Scholarship puede corresponder, en español, tanto a "erudición" ("En sentido amplio, posesión de conocimientos adquiridos mediante el estudio", Moliner, 1992: 1168) como a "escolaridad" ("Situación de escolar; periodo de tiempo durante el cual se asiste a la escuela", ibidem: 1181). De cualquier manera, refiere a la organización de saberes para ser enseñados y aprendidos, por lo que mantiene cercanía semántica con "discípulo" ("El que aprende, con respecto a la persona que le enseña, al centro de enseñanza donde aprende o al maestro o escuela de donde toma sus doctrinas", ibidem: 1010) y por lo tanto, con "disciplina" ("Cada una de las ciencias que se enseñan en un centro de enseñanza o que constituyen un plan de estudios", idem). 
Ordinariamente un poco después fuimos introducidos a las metodologías convencionales: del lado objetivista, encuestas, cuestionarios, experimentos y codificación conductual, o del lado interpretativo, historias de vida, observación participante y entrevistas en profundidad (más recientemente, pueden haber sido partes de los dos conjuntos). [...] De maneras muy deliberadas y específicas fuimos puestos dentro de un campo de escolaridad, lo más específico del cual fue después reforzado por marcos teóricos y métodos convencionales particulares, dentro de una comunidad disciplinaria. Como incipientes teóricos de una cierta escuela, aprendimos las preguntas que hacer y las maneras de responderlas; aprendimos a qué gente leer y a quién ignorar; aprendimos quiénes somos nosotros y quiénes ellos (Anderson, 1996: 5).

Ya Thomas Kuhn (1970) había descrito el proceso de formación de los científicos "en el seno" de un "paradigma", es decir, como inducción a una "comunidad", proceso en el cual la función de los libros de texto es crucial, en términos sobre todo de "normalización" de la ciencia y de la consecuente "disciplinarización" de sus candidatos a practicantes competentes. Pero Anderson da un paso más, al concebir la "teoría como práctica":

La normalización [...] complica profundamente el estudio de la teoría. Nuestro análisis nos obliga a reconocer que la teoría no es sólo un conjunto de proposiciones textuales así denominadas, sino las prácticas en proceso de comunidades intelectuales. [...]

La perniciosa idea de que la teoría puede ser leída en vez de practicada es, al menos en parte, herencia del proyecto positivista. Ese proyecto trató de mostrar la separación entre los postulados de la teoría y la observación. Hay un acuerdo casi total en que ese proyecto fracasó y que las proposiciones y las prácticas están inextricablemente entrelazadas. La teoría, entonces, describe una práctica académica particular que incorpora figuras de liderazgo, textos escriturales, aportes característicos, métodos convencionales, desempeños típicos y miembros practicantes.

Las descripciones esencializantes, del tipo que leemos en los libros de texto, son parte del proceso de normalización, que ponen cosas juntas y mezclan aportes y personas, declarando lo que son. Lo que se oculta, por supuesto, es 
el esfuerzo esencializador. La teoría es trabajo desordenado y contemporizante, en lucha permanente por obtener maestría y suprimir la incertidumbre. Si tuviéramos que comenzar nuestro estudio de la teoría al nivel de las descripciones, estaríamos llegando al espectáculo en el momento de los créditos finales (Anderson, 1996: 7-8).

En el último capítulo de su obra, consecuentemente, después de haber puesto en discusión su marco de análisis en diversos planos jerarquizados, Anderson aborda el análisis de las teorías de la comunicación, a partir de un modelo que supone que

Una teoría debe tener un objeto de explicación, una forma explicativa, un método para relacionar evidencias con postulados, explicaciones características dentro de un rango de desempeño, y una consecuencia de valor. Un análisis de los fundamentos de cualquier teoría se moverá hacia estos fines. Un análisis como ese responde a la pregunta, singular y omniabarcante de "¿qué es lo que tengo que creer que es cierto para vivir una vida de académico a la manera de esta teoría?" (ibidem: 200).

Para identificar las presuntas teorías de la comunicación a las cuales cuestionar, Anderson utilizó siete de los libros de texto disponibles en el mercado que "ofrecen un panorama de la teoría de la comunicación", seleccionados por "haber sobrevivido a la competencia en el mercado alcanzando al menos una segunda edición" (idem) (ver cuadro 1).

Anderson enlistó cualquier mención a una "teoría" o sus sinónimos que estuviera seguida por una cita "centradora" o ejemplificante en estos siete textos. Encontró 249 casos, de los cuales 195 ocurrieron una sola vez. Identificó de esta manera 18 "teorías” mencionadas en al menos tres de los libros, pero sólo una coincidió en cinco casos: la teoría de la disonancia de Leon Festinger. Y Anderson comenta elocuentemente:

Este análisis ciertamente provee clara evidencia del fracaso del proyecto positivista para regularizar y convencionalizar la definición de teoría. Así que hoy, las cuestiones sobre qué debemos reconocer como teoría en general y qué debemos reconocer como teoría de la comunicación en particular, siguen sin resolverse (ibidem: 201). 


\section{CUADRO 1}

LIBROS DE TEXTO DE TEORÍA DE LA COMUNICACIÓN SELECCIONADOS POR ANDERSON (1996: 220) PARA SU ANÁLISIS3

\begin{tabular}{ll}
\multicolumn{1}{c}{ Texto } & \multicolumn{1}{c}{ Edición } \\
\hline $\begin{array}{l}\text { GRIFFIN, E. (1994): A first look at } \\
\text { communication theory. }\end{array}$ & $\begin{array}{l}\text { (2nd ed.) New York: } \\
\text { McGraw Hill. }\end{array}$ \\
\hline $\begin{array}{l}\text { INFANTE, D.A., RANCER, A.S. \& WOMACK, } \\
\begin{array}{l}\text { D.F. (1990): Building communication } \\
\text { theory. }\end{array}\end{array}$ & $\begin{array}{l}\text { Prospect Highs, IL: Wave- } \\
\text { land Press. }\end{array}$ \\
\hline JABLIN, F.M., PUTNAM, L.L., ROBERTS, & Newbury Park, CA: Sage. \\
$\begin{array}{l}\text { K.H. \& PORTER, L.W. (1987): Handbook of } \\
\text { organizational communication. }\end{array}$ & \\
\hline $\begin{array}{l}\text { LITTLEJOHN, S.W. (1992): Theories of } \\
\text { human communication. }\end{array}$ & (4th ed.) Belmont, CA: \\
\hline $\begin{array}{l}\text { McQUAIL, D. (1987): Mass communication } \\
\text { theory. }\end{array}$ & (2ndsworth. \\
\hline $\begin{array}{l}\text { SEVERIN, W. J. \& TANKARD, J.W.Jr. (1992): } \\
\text { Communication theories: origins, methods, Park, } \\
\text { and uses in the mass media. }\end{array}$ & (3rd ed.) New York: Long- \\
\hline $\begin{array}{l}\text { TRENHOLM, S. (1991): Human } \\
\text { communication theory. }\end{array}$ & (2nd ed.) Englewood Cliffs, \\
\hline
\end{tabular}

El mismo autor se sorprende de los resultados: entre las 18 "teorías de la comunicación" no hay representación de las teorías marxista, feminista o crítica. También están ausentes los estudios culturales, la hermenéutica, la teoría de la acción social y la teoría de la estructuración, al igual que el estructuralismo, el existencialismo, la fenomenología, la teoría de la ideología y la de la hegemonía. Pero nueve de las 18 "podrían ajustarse a alguna definición de cognitivismo" (ibidem: 202), y el resto se pueden reconocer como "accionales" y "discursivas" (ibidem: 217). Sólo por curiosidad, pues la consistencia epistemológica de las

3 De estos siete libros, sólo uno está traducido y disponible en el mercado de habla hispana: Introducción a la teoría de la comunicación de masas de Denis McQuail (Barcelona: Paidós Comunicación, 1990). 
teorías no es el objeto de este trabajo, en el cuadro 2 se citan las 18 "teorías de la comunicación" identificadas por Anderson en los siete libros de texto analizados.

\section{CUADRO 2}

“TEORÍAS DE LA COMUNICACIÓN" MENCIONADAS EN SIETE LIBROS DE TEXTO DE TEORÍA DE LA COMUNICACIÓN SELECCIONADOS POR ANDERSON (1996: 203-204) PARA SU ANÁLISIS

$\begin{array}{rr}\text { Teoría (autor citado*) } & \begin{array}{c}\text { Presencia en } \\ \text { libros de texto }\end{array}\end{array}$

\begin{tabular}{lc}
\hline $\begin{array}{l}\text { Agenda setting (Establecimiento de agenda) } \\
\text { (McCombs \& Shaw, 1972) }\end{array}$ & 4 \\
\hline $\begin{array}{l}\text { Cognitive dissonance (Disonancia cognoscitiva) } \\
\text { (Festinger, 1957) }\end{array}$ & 5 \\
\hline $\begin{array}{l}\text { Communication pragmatics (Pragmática de la } \\
\text { comunicación) (Watzlawick, Bavelas, \& Jackson, } \\
1967)\end{array}$ & 3 \\
\hline
\end{tabular}

Constructivism (Constructivismo) (Delia, O'Keefe \& 3

O’Keefe, 1982)

Coordinated management of meaning (Administración 3

coordinada del significado) (Pearce \& Kronen, 1980)

Cultivation analysis (Análisis del cultivo) (Gerbner, 4

Gross, Morgan \& Signorelli, 1986)

Diffusion of innovations (Difusión de innovaciones) 4

(Rogers, 1962)

Dramatism (Dramatismo) (Burke, 1968) 3

Meaning (Significado) (Richards, 1936) 3

Narrative theory (Teoria narrativa) (Fisher, 1987) 3

Rhetorical sensitivity model (Modelo de sensibilidad 3

retórica) (Hart \& Burks, 1972)

Social judgement theory (Teoría del juicio social)

4

(Sherif \& Hovland, 1961)

* No se incluyen las referencias completas, sólo se indica el año para ubicación de la cita. 


\begin{tabular}{lc}
\multicolumn{1}{c}{ Teoría (autor citado*) } & $\begin{array}{c}\text { Presencia en } \\
\text { libros de texto }\end{array}$ \\
\hline $\begin{array}{l}\text { Source credibility (Credibilidad de la fuente) } \\
\text { (Andersen \& Clevenger, 1963) }\end{array}$ & 3 \\
\hline $\begin{array}{l}\text { Speech act theory (Teoría de los actos de habla) } \\
\text { (Searle, 1969) }\end{array}$ & 3 \\
\hline $\begin{array}{l}\text { Spiral of silence (Espiral del silencio) (Noelle- } \\
\text { Newmann (1991) }\end{array}$ & 4 \\
\hline $\begin{array}{l}\text { Theory of reasoned action (Teoría de la acción } \\
\text { razonada) (Ajzen \& Fishbein, 1970) }\end{array}$ & 3 \\
\hline $\begin{array}{l}\text { Uncertainty reduction theory (Teoría de la reducción } \\
\text { de incertidumbre) (Berger \& Calabrese, 1975) }\end{array}$ & 4 \\
\hline $\begin{array}{l}\text { Uses and gratifications (Usos y gratificaciones) (Katz, } \\
\text { Blumler \& Gurevitch, 1974) }\end{array}$ & 3 \\
\hline
\end{tabular}

Anderson concluye su estudio (y su libro) con un "análisis relacional" de las 18 teorías (más tres que introduce él mismo: la de la estructuración, de la acción social y los estudios culturales), para determinar estadísticamente los "valores de inconmensurabilidad" entre ellas. Pero su punto de partida lo detiene:

La comparación de teorías que emergen de dominios epistémicos diferentes no puede ser hecha honestamente sobre una base proposicional, frase por frase. Esa comparación tiene que ser dirigida al nivel de la comunidad de práctica ¿Cuál es el programa de investigación que es sostenido por esta teoría? ¿Qué hacen los defensores de una determinada teoría? ¿Qué vida es la que viven? ¿Qué consecuencias resultan?

(...) Una parte de los procesos sociopolíticos de la educación de posgrado que debería de ser cuidadosamente desvelada es la economía de aprendices que caracteriza a muchos programas. Con frecuencia los estudiantes son programados para aceptar un modo particular de pensar por un sistema de asignaturas, y así son sistemáticamente desalentados de examinar otros puntos de vista o epistemologías competidoras. El resultado es una colección de jóvenes colegas complacientemente entusiasmados con las mismas ideas (ibidem: 219). 
Además de la muy evidente insatisfacción que expresa Anderson con respecto a los procesos de formación de investigadores de la comunicación (en Estados Unidos, por supuesto), en su obra quedan de manifiesto dos cuestiones más, de gran importancia para el campo académico: por una parte, la dispersión (e incluso inconmensurabilidad) de los referentes teóricos en los que se sustenta intelectualmente el campo ${ }^{4} \mathrm{y}$, por otra, la incapacidad de sus "agentes" más destacados para reconocer (y reorientar) los usos y consecuencias prácticas de la bibliografía disponible, especialmente la diseñada para operar como "libros de texto".

Con inquietudes quizá similares a las de Anderson, pero con una propuesta diferente, no menos heterodoxa, Elihu Katz, John Durham Peters, Tamar Liebes y Avril Orloff editaron un libro en 2003 que resulta provocador desde su título: Textos canónicos en la investigación de medios: ¿hay alguno?, ¿debe haber?, ¿qué tal éstos? Desde la introducción, los editores reconstruyen las objeciones de los colegas que conocieron su proyecto, resumidas en "los peligros de la constricción y la necesidad de libertad — con respecto a la autoridad, a la disciplina, al método, a la tradición" (Katz et al., 2003: 1).

Queremos contribuir a la comunidad de académicos que están interesados en el campo — sí, el campo — interdisciplinario de investigación de la comunicación. Es simple romanticismo negar que tal campo existe, incluso si está todavía luchando por autodefinirse. Dejamos para los estudios culturales la resistencia a convertirse en un campo. En lo que concierne a los estudios de medios, la evidencia de una docena o más de revistas especializadas sugiere que están en marcha procesos disciplinarios — no en algún sentido monolí-

4 Para ilustrar el grado de dispersión, puede referirse a Bryant y Miron (2004), quienes realizaron un análisis bibliométrico y de contenido de las tres revistas académicas más prestigiadas en Estados Unidos entre 1956 y 2000, para detectar cambios en las teorías de la comunicación de masas empleadas en las investigaciones publicadas. En una muestra de 1806 artículos, encontraron " 1393 referencias a 604 teorías, paradigmas científicos generales y escuelas de pensamiento que han sido desarrolladas por académicos de la comunicación o que han sido importadas de campos vecinos para explorar fenómenos de comunicación de masas" (ibidem: 664). 
tico, sino en un diálogo útil entre teorías, métodos y "fronteras". Un campo es un proceso de constante tamizar lo que merece ser desechado y lo que merece ser continuado (ibidem: 2).

La idea de identificar "textos canónicos" se basa precisamente en esa concepción, y depende explícitamente, como la propuesta de Anderson, del sentido que pueda otorgarle una determinada comunidad de practicantes. La defensa del concepto de "canon" ("textos, obras, artefactos que son distinguidos como objetos relativamente duraderos por miembros de una comunidad de indagación") se basa en el proceso de "apropiación" y se asocia con dos metáforas mertonianas: "pararse en los hombros de gigantes" y "dar a luz a los propios progenitores" (idem).

Los textos propuestos para la "canonización", —-"o dicho menos controversialmente, fundacionales de los estudios de medios" - son trece, asociados con cinco "escuelas" de investigación de la comunicación, sobre cada uno de los cuales los autores escribieron un ensayo crítico de re-lectura. La propuesta misma de las "escuelas", así como la selección de los textos y su ubicación en estas categorías, es objeto de discusión, junto con las razones por las cuales los autores consideran "canonizables" a esos aportes históricos. En el cuadro 3 se señalan los textos estudiados.

Sobre las "escuelas", los editores mantienen reservas: por un lado, se excusan por las ausencias de París, "famosa por sus estudios semióticos del cine y la cultura", y de Yale, "donde se intentó estudiar experimentalmente la persuasión masiva" (ibidem: 6). Pero, por otro, reconocen la relativa inconsistencia de la clasificación:

Las diferencias intra-escuelas son tales que hubiera sido igualmente bueno (o mejor) agrupar los textos temáticamente. De hecho, un eje subyacente en los ensayos contenidos en el libro - que los editores no habían anticipado- es que la memoria colectiva del campo pudo haberse equivocado al catalogar esos textos por su procedencia y no por su tema. Así, nuestros autores arguyen que Herzog, y hasta Lazarsfeld y Merton, pero con certeza Lang y Lang, merecen un lugar de honra entre los teóricos críticos, mientras que Benjamin podría ser también ubicado entre los teóricos tecnologicistas, no obstante su membresía en la Escuela de Frankfurt (ibidem: 7). 


\begin{tabular}{|c|c|}
\hline \multicolumn{2}{|c|}{$\begin{array}{l}\text { TEXTOS ANALIZADOS COMO “CANÓNICOS” EN LA OBRA } \\
\text { EDITADA POR KATZ, PETERS, LIEBES Y ORLOFF (2003)5 }\end{array}$} \\
\hline Texto (fecha de publicación en inglés) & Autor del ensayo \\
\hline \multicolumn{2}{|l|}{ Escuela de Columbia } \\
\hline $\begin{array}{l}\text { LAZARSFELD \& MERTON: "Mass communication, } \\
\text { popular taste, and organized social action" (1948) }\end{array}$ & $\begin{array}{l}\text { Peter Simondson \& } \\
\text { Gabriel Weimann }\end{array}$ \\
\hline HERZOG: "On borrowed experience" (1941) & Tamar Liebes \\
\hline \multicolumn{2}{|l|}{ Escuela de Frankfurt } \\
\hline $\begin{array}{l}\text { HORKHEIMER \& ADORNO: “The culture industry” } \\
\text { (1972) }\end{array}$ & John Durham Peters \\
\hline $\begin{array}{l}\text { BENJAMIN: "The work of art in the age of } \\
\text { mechanical reproduction" (1968) }\end{array}$ & Paddy Scanell \\
\hline $\begin{array}{l}\text { LOWENTHAL: "The triumph of the mass idols" } \\
\text { (1961) }\end{array}$ & Eva Illouz \\
\hline \multicolumn{2}{|l|}{ Escuela de Chicago } \\
\hline $\begin{array}{l}\text { WIRTH: “Consensus and mass communication" } \\
\text { (1947) }\end{array}$ & Eric W. Rothenbuhler \\
\hline $\begin{array}{l}\text { LANG AND LANG: "McArthur day in Chicago" } \\
\text { (1953) }\end{array}$ & $\begin{array}{l}\text { Elihu Katz \& Daniel } \\
\text { Dayan }\end{array}$ \\
\hline $\begin{array}{l}\text { Hay traducciones al español disponibles de apena } \\
\text { Lazarsfeld y Merton: "Comunicación de masas, } \\
\text { social organizada", en Moragas (ed.), Sociologic } \\
\text { masas, II: Estructura, funciones y efectos (Barcel } \\
\text { Horkheimer y Adorno: "La industria cultural" e } \\
\text { cultural y sociedad de masas (Caracas: Monte Áv } \\
\text { arte en la época de la reproducción mecánica" en } \\
\text { y comunicación de masas (México: Fondo de Cu } \\
\text { McLuhan: La comprensión de los medios como } \\
\text { (México: Diana, 1969); Williams: Cultura y socie } \\
\text { va Visión, 2001); Hall: "Codificación y descodif } \\
\text { levisivo" en Cuadernos de Información y Comun } \\
\text { 2004); Mulvey: Placer visual y cine narrativo (V }\end{array}$ & $\begin{array}{l}\text { la mitad de estos textos: } \\
\text { ustos populares y acción } \\
\text { de la comunicación de } \\
\text { na, Gustavo Gili, 1985); } \\
\text { Bell y otros, Industria } \\
\text { la, 1974); Benjamin: "El } \\
\text { Curran et al., Sociedad } \\
\text { ltura Económica, 1981); } \\
\text { extensiones del hombre } \\
\text { dad (Buenos Aires: Nue- } \\
\text { cación en el discurso te- } \\
\text { cación, núm. } 9 \text { (Madrid, } \\
\text { lencia: Fundación Insti- }\end{array}$ \\
\hline
\end{tabular}


Texto (fecha de publicación en inglés)

HORTON \& WOHL: "Mass communication and para-social interaction" (1956)

Escuela de Toronto INNIS: The bias of communication (1951)

MCLUHAN: Understanding media (1964)

Estudios culturales británicos

WILLIAMS: Culture and society (1958)

HALL: "Encoding/decoding" (1980)
Autor del ensayo

Don Handelman Menahem Blondheim

Joshua Meyrowitz John Durham Peters

Michael Gurevitch \&

Paddy Scanell

MULVEY: "Visual pleasure and narrative cinema" Yosefa Loshitzky (1975)

La clasificación de los textos en categorías históricas o temáticas es, entonces, otro problema evidente del campo de la comunicación, y quizá un factor de distracción adicional en el caso del atrevido proyecto de Katz y colegas. Una reseña crítica de la obra resume su juicio en una frase lapidaria: "Canonic texts in media research funciona porque no trata a sus nominados como canónicos. Quizá los gigantes poblaron la tierra alguna vez, pero apenas comenzamos a registrar sus huellas" (Pooley, 2005: 203).

Un tercer proyecto colectivo que cabe referir en esta sección, aun más radical, es el que sustenta el libro editado por Gregory Shepherd, Jeffrey St. John y Ted Striphas (2006), La comunicación como... Perspectivas sobre la teoría, una colección de 27 ensayos muy breves que, al decir de sus editores, tres académicos estadounidenses,

descansa en dos premisas principales: primero que la comunicación es -o debe ser- un concepto en disputa; y segundo, que los argumentos sobre el significado, valor y utilidad de la comunicación tienen que ser generativos (ibidem: IX).

Así, convocaron a otros académicos a argumentar en breve sobre su convicción más básica, sobre su "postura" con el menor "aparato crítico" posible, sobre lo que es, teóricamente, la comunicación. A cada uno de los autores 
se le pidió que pensara así: $m i$ postura es la más útil para el estudio y la práctica de la comunicación. Mi metáfora, mi analogía, mi modelo. Esto, no aquello, por estas razones. Esto es en lo que creo y por qué lo creo, y esta es la diferencia que hace (ibidem: XII). [Pero advierten que] este libro no es un ejercicio o un ejemplo de pluralismo teórico, o de la creencia de que todas las teorías tienen el mismo mérito si se entienden y aprecian en sus propios términos.

Por el contrario, "es un rechazo deliberado del supuesto tácito en la comunicación contemporánea de que una pluralidad indiferenciada de teorías es de alguna manera algo bueno" (ibidem: XII, XIV). El proyecto surge de la insatisfacción con una de las "tendencias clave" del campo, que "constriñe la imaginación de la teoría y de los teóricos de la comunicación":

Al menos desde el segundo cuarto del siglo XX, una orientación fuertemente empiricista ha guiado gran parte de la investigación y de la escritura académicas, incluyendo las de la comunicación. El legado principal de esta orientación ha sido un conjunto de expectativas sobre lo que es una "buena" teoría. Las teorías, nos dice el empiricismo, deben demostrar una clara conexión con una realidad observable y deben aterrizarse en una amplia literatura académica para aparecer como creíbles. Por diversas y complejas razones, un enjambre de procedimientos (incluyendo reglas para las referencias, notas de pie de página y similares) vino a determinar si una idea valía la pena, era buena, creíble o verdadera. La poderosa creencia humanística de que el sentido inherente de una idea -su lugar en una comunidad, su emergencia dentro de una tradición identificable, o su reflejo de una manera de vivir- es la medida más fuerte del valor de una idea, fue barrida por el método. En un periodo asombrosamente breve, el nuevo paradigma empiricista comenzó a declarar que lo que hace ser "buena" a una teoría es que pueda ser probada, donde la prueba se confina a las reglas normativas y potencialmente limitantes de la medición y la referencia. Eso es lo que intentamos evitar en esta colección (ibidem: XV).

El rango de posturas expresadas en este proyecto de "emancipación de los angostos confines del empiricismo" es amplio, pero no exhaustivo, ni siquiera con respecto a la academia estadounidense. 
Pero intenta provocar el debate sobre las posturas subyacentes en las "teorías de la comunicación" sostenidas y enseñadas, y sobre las implicaciones de la diversidad en el entorno:

Este puede ser un libro sobre la comunicación y las teorías de la comunicación, pero también, y con la misma importancia, es un libro sobre las consecuencias intelectuales, políticas y éticas de las opciones mismas que nos llevan a formar y a poner en acto concepciones particulares de la comunicación" (ibidem: XVI).

La organización del libro, al ordenar y separar contribuciones tituladas metafóricamente, induce inevitablemente sesgos a la lectura. Por ello los editores proponen tres preguntas a los lectores: “¿De qué manera difieren las posturas aparentemente consistentes o compatibles?, ¿por qué difieren? y, ¿cuál es la significación mayor de esas diferencias?" (ibidem: XIX). Finalmente, apuestan por evitar dos riesgos antagónicos para la "teorización creativa": el dogmatismo y el pluralismo teórico. En el cuadro 4 se despliegan los contenidos de esta obra:

\section{CUADRO 4}

PERSPECTIVAS PROPUESTAS PARA TEORIZAR SOBRE LA COMUNICACIÓN

EN EL LIBRO EDITADO POR SHEPHERD, ST. JOHN Y STRIPHAS (2006)

\begin{tabular}{ll}
\multicolumn{1}{c}{ Texto } & \multicolumn{1}{c}{ Autor del ensayo } \\
\hline La comunicación como... hacer (making) & \\
\hline Relationality (Relacionalidad) & Celeste M. Condit \\
\hline Ritual (Ritual) & Erick W. Rothenbuhler \\
\hline Transcendence (Trascendencia) & Gregory J. Shepherd \\
\hline Constructive (Constructiva) & Katherine Miller \\
\hline A practice (Una práctica) & Robert T. Craig \\
\hline La comunicación como... materialización (materializing) \\
\hline Collective memory (Memoria colectiva) & Carole Blair \\
\hline Vision (Visión) & Cara A. Finnegan \\
\hline Embodiment (Incorporación) & Carolyn Marvin \\
\hline Raced (Raza) & Judith N. Martin \& \\
& Thomas K. Nakayama
\end{tabular}


Texto

Autor del ensayo

\begin{tabular}{ll}
\hline Social identity (Identidad social) & Jake Harwood \\
\hline Techné (Techné) & Jonathan Sterne \\
\hline La comunicación como... contextualización (contextualizing) \\
\hline Dialogue (Diálogo) & Leslie A. Baxter \\
\hline Autoethnography (Autoetnografía) & Arthur P. Bochner \& \\
& Carolyn S. Ellis \\
\hline Storytelling (Narración de historias) & Eric E. Peterson \& Kristin \\
& M. Langellier \\
\hline Complex organizing (Organización compleja) & James R. Taylor \\
\hline Structuring (Estructuración) & David R. Seibold \& Karen \\
& Kroman Myers \\
\hline La comunicación como... politización (politicizing) \\
\hline Political participation (Participación política) & Todd Kelshaw \\
\hline Deliberation (Deliberación) & John Gastil \\
\hline Diffusion (Difusión) & James W. Dearing \\
\hline Social influence (Influencia social) & Frank Boster \\
\hline Rational argument (Argumento racional) & Robert C. Rowland \\
\hline Counterpublic (Contrapúblico) & Daniel C. Brouwer \\
\hline La comunicación como... cuestionamiento (questioning) \\
\hline Dissemination (Diseminación) & John Durham Peters \\
\hline Articulation (Articulación) & Jennifer Daryl Slack \\
\hline Translation (Traducción) & Ted Striphas \\
\hline Communicability (Comunicabilidad) & Briankle G. Chang \\
\hline Failure (Fracaso) & Jeffrey St.John \\
\hline
\end{tabular}

Estas tres muestras de la reflexión reciente sobre la constitución intelectual y social del campo académico de la comunicación en Estados Unidos (y sus extensiones "internacionales") -ninguna de las cuales está traducida al español- pueden servir para indicar la complejidad que hay "detrás" de la pregunta por la relación entre programas educativos y fuentes bibliográficas, pues las "confluencias teóricas y metodológicas" supuestas para la normalización disciplinaria de los estudios sobre la comunicación son cada vez más difíciles de identificar, aun desde perspectivas simplificadoras o dogmáticas (que son quizá más frecuentes e influyentes que las "críticas" como las aquí citadas), en tanto que 
remiten a procesos de múltiples dimensiones, que reconstruyen (y consolidan) permanentemente las relaciones del presente del estudio de la comunicación con sus pasados y sus futuros posibles.

\section{DOS BIBLIOGRAFÍAS MEXICANAS}

Un propósito que bien puede entenderse como "constructivo" en el sentido de los antes reseñados, es el que proviene del proyecto del Grupo hacia una Comunicología Posible (GUCOM), formado a iniciativa y alrededor del investigador mexicano Jesús Galindo. De entre la amplia bibliografía que ha generado este grupo en los cinco años recientes, pueden destacarse en esta ocasión dos trabajos (Galindo et al., 2005; Rizo, 2006), donde se exponen los planteamientos y resultados de su exploración de la fase bibliográfica del proyecto, que debe entenderse como parte de una propuesta mucho más amplia, pues el GUCOM

Pretende dotar de consistencia epistemológica y teórica a un campo del saber que ha generado mucha investigación empírica pero que no termina de definir con consistencia su especificidad frente a otras disciplinas. La propuesta de GUCOM se plantea como hipótesis; no se presenta, por tanto, como una forma de organización teórica cerrada y terminada del campo científico de la comunicación. Más bien, se trata de un proyecto en construcción que va tomando forma pero que se redefine y reformula constantemente (Rizo, 2006: 181).

Para el grupo, "la historia de la comunicología como disciplina" incluye, "al menos, siete fuentes teóricas básicas": la economía política, la semiolingüística, la sociología funcionalista, la sociología fenomenológica, la sociología crítica-cultural, la psicología social y la cibernética (ibidem: 183). ¿Por qué reconstruir la historia del "pensamiento comunicacional" en referencia a estas siete "fuentes" y al mismo tiempo generar el marco conceptual fundante de la disciplina llamada "comunicología"? (que "es el nombre de la ciencia de la comunicación", Galindo, 2005: 9) Según este, la propuesta es "compleja pero sencilla":

Se trata de reconstruir el espacio conceptual de la comunicación en la historia del pensamiento comunicacional, partiendo de la historia "oficial" del campo 
académico de la comunicación en México, y de ahí hacia América Latina, Europa y Estados Unidos. A esto le llamamos construcción a posteriori de las fuentes históricas del pensamiento comunicacional. Y por otra parte, se trata de proponer una perspectiva, que en forma constructiva, permita ordenar al pensamiento comunicacional de manera general y particular a partir de categorías y premisas generadoras. A esto le llamamos la perspectiva $a$ priori. Una y otra se nutren mutuamente (ibidem, 2005: 14).

Para la "construcción a posteriori", el grupo emprendió en 2003 la tarea de identificar y analizar Cien libros hacia una comunicología posible (Galindo et al., 2005), que resultaron ser 140. Los criterios de selección fueron dos (o tres):

que los libros aporten sustento a una ciencia posible y que ya estén presentes en el campo académico. Estos dos criterios se complementan con un tercero que es básico, que los textos estén en español, hayan sido escritos o publicados, en principio, en nuestra lengua, o que sean traducciones de otra (Galindo, 2005: 19)6.

Del extenso análisis descriptivo que los autores elaboran a propósito de los indicadores con que guiaron la revisión de los libros seleccionados, de los cuales su libro incluye una reseña crítica de cada uno, cabe rescatar aquí solamente la composición del corpus y la larga serie de "hipótesis" que surgen sobre "la configuración del campo académico de la comunicación a partir de la selección -por separado- de obras originalmente escritas en español y obras escritas en otros idiomas" (Galindo y Rizo, 2005: 77).

Galindo, Karam y Rizo (2005) incluyeron en su obra, siguiendo los criterios de selección ya mencionados, 75 obras de origen extranjero (Europa y América del Norte) y 65 provenientes “del ámbito iberoame-

6 Probablemente la razón para adoptar este criterio, que parece al menos tan "etnocéntrico" como los más típicamente estadounidenses, sea la referencia "histórica" de surgimiento del proyecto en el campo académico mexicano, desde un programa de doctorado en comunicación, abierto en 2002, que fue suprimido antes de graduar a su primera generación (Galindo, 2005: 10-14). 
ricano", de las cuales 36 son mexicanas. Pero en los cuadros en que resumen las diversas clasificaciones analíticas (Galindo y Rizo, 2005), los totales no suman $140^{7}$. Aunque la reseña de cada obra es muy ilustrativa del juicio general que orienta el proyecto (y a cada uno de sus tres autores), es difícil encontrar las evidencias agregadas de algo más que de la premisa "de entrada" de la "pobreza" y dispersión conceptual del campo. Más adelante, en esta misma sección, se retoman algunos datos de esta selección de textos, al compararlos con otra, obtenida mediante un procedimiento diferente.

Pero conviene recuperar el análisis que, en el marco del mismo proyecto, realiza Marta Rizo sobre quince libros de texto o "manuales" sobre teorías de la comunicación, disponibles en el campo mexicano, seleccionados porque, entre otros criterios,

presentan un panorama amplio de las teorías de la comunicación ... presentan revisiones históricas... y han tenido cierta presencia en el campo académico de la comunicación en México, algo que puede observarse si se revisan las bibliografías de las materias de teorías de la comunicación en varios planes de estudio de universidades mexicanas (2006: 199).

Los libros analizados por Rizo se exponen en el cuadro 5:

\section{CUADRO 5}

LIBROS DE TEXTO DE TEORÍA DE LA COMUNICACIÓN SELECCIONADOS POR RIZO (2006: 198) PARA SU ANÁLISIS

Texto Edición

TOUSSAINT, F. (1975): Crítica de la México: Trillas ANUIES

información de masas.

\begin{tabular}{ll}
\hline $\begin{array}{l}\text { SMITH, A.G. (comp.) (1976): Comunicación y } \\
\text { cultura (3 vols.) }\end{array}$ & $\begin{array}{l}\text { Buenos Aires: Nueva } \\
\text { Visión }\end{array}$ \\
\hline PAOLI, J.A. (1977): Comunicación e & México: Trillas
\end{tabular}

información, perspectivas teóricas.

7 Quizá por la inclusión de algunas obras que los autores llaman "multirregión". 
Texto

MORAGAS, M. de (1981): Teorías de la comunicación de masas. Investigaciones sobre

medios en América y Europa.
Edición

Barcelona: Gustavo Gili

CORRAL C., M. (1986): La ciencia de la

México: Trillas

comunicación en México. Origen, desarrollo y

situación actual.

WOLF, M. (1987): La investigación de

Buenos Aires: Paidós

la comunicación de masas. Crítica y

perspectivas.

RODRIGO A., Miquel (1989): Los modelos de Madrid: Tecnos

la comunicación.

McQUAIL, D. (1990): Introducción a la teoría Barcelona: Paidós

de la comunicación de masas.

LAZAR, J. (1996): La ciencia de la México: Publicaciones

comunicación. Cruz

LOZANO, J.C. (1996): Teoría e investigación México: Alhambra

de la comunicación de masas.

MIEGE, B. (1996): El pensamiento

México: UIA

comunicacional.

MATTELART, A. y M. (1997): Historia de las Barcelona: Paidós

teorías de la comunicación.

RODRIGO A., Miquel (2001): Teorias de Barcelona: U.A.B.

la comunicación. Ámbitos, métodos y

perspectivas.

TORRICO V., E. (2004): Abordajes y periodos Buenos Aires: Norma

de la teoría de la comunicación.

IGARTÚA, J.J. y M.L. HUMANES (2004): Teoría Madrid: Síntesis

e investigación en comunicación social.

De inmediato llama la atención que 10 de los 15 libros hayan sido escritos originalmente en español, y también que cinco de ellos (los dos de Rodrigo, el de Lazar, el de Torrico y el de Igartúa y Humanes) no estén presentes en la lista de 140, aunque los dos últimos son muy recientes. Pero también es notable el análisis realizado por Rizo, muy similar en su procedimiento al de Anderson, a quien no cita. Aunque aquí, más allá de 
constatar las divergencias, a partir de las "formas de nombrar a las teorías de la comunicación" en cada uno de los 15 libros, la autora los compara con las siete "fuentes históricas" y las cuatro "dimensiones comunicológicas" (difusión, interacción, expresión, estructuración) de la propuesta de la comunicología posible, y señala el "énfasis" de cada uno ("el abordaje teórico de la comunicación con mayor presencia y fuerza en cada una de las obras analizadas", ibidem: 200). En resumen:

La sociología funcionalista es la fuente teórica predominante en las obras, con un total de 38 referencias. En segundo lugar, la semiolingüística -con 22 - y la sociología crítica-cultural - con 20- son las fuentes de mayor presencia. Las restantes ocupan una importancia menor en los libros analizados, siendo la sociología fenomenológica la fuente teórica con menor número de referencias -6 en total. (...) La difusión -con 46 de las 120 referencias- y la estructuración -con un total de 43-, son las dimensiones más destacadas en el conjunto de las obras. La expresión, con 18, y la interacción, con 12, tienen una presencia mucho menor (ibidem: 203-204).

Para ella, "el análisis anterior revela cuestiones que, si bien no son nuevas, en pocas ocasiones han sido objetivadas en análisis empíricos concretos" (ibidem: 204), afirmación en la que es importante coincidir, para subrayar que su análisis es muy consistente en relación con los propósitos declarados y las operaciones analíticas realizadas, de donde surgen además varias "apreciaciones" (que no "conclusiones"), que vale la pena recuperar: que se vuelve a poner de manifiesto "la amplitud conceptual que abarca el mundo de las teorías de la comunicación"; que "la difusión, los medios, siguen siendo el objeto por excelencia del campo académico de la comunicación"; que "la comunicación se sigue abordando como fenómeno relacionado con aspectos más amplios como la cultura, la economía y la política"; y que "este texto (...) contribuye a continuar el debate acerca del estatuto disciplinar de la ciencia de la comunicación"8 (ibidem: 207-208).

8 Y por supuesto, desde fuera del proyecto, a apreciar la dificultad de compatibilizar estos resultados de la perspectiva a posteriori con los propósitos de la construcción a priori de un marco "sistémico" integrador. 
La capacidad de fundamentar el debate "en análisis empíricos concretos", además y en combinación con la definición de posturas y proyectos de intervención sobre el campo académico que se toma como referencia, puede contribuir a una reducción de las "distancias" - $\mathrm{O}$ al menos a desalentar su consideración como irreductibles- entre agentes académicos que adoptan "estrategias" diferentes en el campo (Bourdieu, 1988, 2000). Por ello se propone comparar -y quizá complementar- la bibliografía de la comunicología posible con la que surge de un recuento empírico también mexicano, como parte de un proyecto de investigación que comparte, al menos, la insatisfacción con el estado actual de consolidación científica de los estudios sobre la comunicación en México y en el mundo.

El proyecto La constitución científica del campo académico de la comunicación en México y en Brasil: análisis comparativo, en proceso desde 2005, tiene el propósito de

analizar comparativamente la constitución de redes científicas y núcleos de especialización, mediante la identificación de convergencias temático-referenciales y teórico-metodológicas en las tesis de posgrado9 ${ }^{9}$, en el contexto de los procesos de institucionalización, profesionalización y legitimación del campo académico de la comunicación en México y en Brasil (Fuentes, 2004).

El punto de partida, evidentemente, es la recuperación de las referencias bibliográficas presentes en las tesis defendidas entre 1996 y 2005.

Para el caso mexicano, se trabajó con las tesis de maestría de los cinco programas acreditados por el Padrón Nacional de Posgrados de SEP/CONACyT (las maestrías en comunicación de la UNAM, la UIA, la UdeG, el ITESO y el ITESM), y una selección de tesis de doctorado con tema "comunicacional", presentadas en varias universidades mexicanas durante el

9 Se elegió centrar el análisis en las tesis de posgrado a partir del supuesto de que en ellas se explicitan las fuentes bibliográficas y los procedimientos metódicos de una manera más rigurosa que en otros productos de la investigación académica, además de que representan la instancia fundamental de objetivación de los procesos de reproducción y renovación de un campo académico. 
periodo elegido. Se recuperaron 397 tesis ${ }^{10}$, en las que se contabilizaron 35,814 referencias (promedio de 179.9 por tesis), de las cuales 17,449 (promedio de 87.7 por tesis), $48.7 \%$, son en sentido estricto referencias bibliográficas (es decir, a libros). La base de datos formada con estas permitió detectar los textos más citados y asociar estas frecuencias con otras variables (como la institución, el año o el tema de las tesis, así como el origen de los libros, su antigüedad o sus características editoriales). Por ahora, conviene solamente hacer mención que de los 9,594 libros citados, sólo 791 están referidos en al menos $1 \%$ de las tesis, es decir, en cuatro o más de ellas, y únicamente 14 al menos en 10\% (40 o más) de las tesis. Estos últimos se anotan en el cuadro 6.

\section{CUADRO 6}

LIBROS MÁS FRECUENTEMENTE CITADOS EN 397 TESIS DE POSGRADO EN COMUNICACIÓN EN MÉXICO (1996-2005), (FUENTES EN PROCESO)

\begin{tabular}{llc}
\multicolumn{1}{c}{ Libro * } & Ediciones citadas & Frec. \\
\hline THOMPSON, John B. (1993) Ideología y cul- & México: UAM-X & 79 \\
tura moderna. Teoría crítica social en la era & [California: & \\
de la comunicación de masas. [Ideology and & Stanford & \\
modern culture, 1990]. & University Press] & \\
\hline MARTíN BARBERO, Jesús (1987) De los me- & México: Gustavo & 67 \\
dios a las mediaciones: comunicación, cul- & Gili [London: & \\
tura y hegemonía. [Communication, culture & Sage] \\
and hegemony, from the media to mediations, & & \\
1993]. & & \\
\hline BERGER, Peter y Thomas LUCKMANN (1968) & Buenos Aires: & 57 \\
La construcción social de la realidad. [The & Amorrortu. [New & \\
social construction of reality, 1967]. & York: Anchor & \\
& Books] & \\
\hline
\end{tabular}

* Entre corchetes, título y año de publicación de otra edición, también citada en las tesis.

1041 de doctorado (varios programas); y de maestría, 112 de la UNAM, 84 de la UIA, 41 de la UdeG, 30 del ITESO y 89 del ITESM, es decir, aproximadamente $85 \%$ de las tesis existentes. 
Libro

Ediciones citadas Frec.

\begin{tabular}{lll}
\hline WOLF, Mauro (1985) La investigación de la co- & Buenos Aires: & 57 \\
municación de masas. Crítica y perspectivas. & Paidós & \\
\hline CASTELLS, Manuel [1996-1998] (1999) La & México: Siglo XXI & 54
\end{tabular}
era de la información. Economía, sociedad y cultura (3 volúmenes).

THOMPSON, John B. (1998): Los media y la Barcelona: Paidós 51 modernidad: Una teoría de los medios de [California: comunicación, [The media and modernity. A Stanford social theory of the media, 1995]. University Press]. GEERTZ, Clifford (1987) La interpretación de Barcelona: Gedisa 47 las culturas. [The interpretation of cultures, 1973].

GIDDENS, Anthony (1995) La constitución de Buenos Aires:

la sociedad. Bases para la teoría de la estruc- Amorrortu turación, [The constitution of society. Outline] [Berkeley \& Los of the theory of structuration, 1984]. Angeles: U. of California Press].

TAYLOR, Steve J. y BOGDAN (1986) Introduc- Barcelona: Paidós ción a los métodos cualitativos de investiga- [Canada: Wiley \& ción. La búsqueda de significados. [Introduc- Sons] tion to qualitative research methods]. BOURDIEU, Pierre [1984] (1990) Sociología y México: cultura. CONACULTA/

Grijalbo

LOZANO RENDÓN, José Carlos (1996). Teoría México: Alhambra

e investigación de la comunicación de masas.

GARCÍA CANCLINI, Néstor (1990) Culturas

híbridas. Estrategias para entrar y salir de la modernidad.

México:

CONACULTA/

Grijalbo

HABERMAS, Jürgen (1989) Teoría de la ac- Madrid: Taurus ción comunicativa (2 tomos).

OROZCO GÓMEZ, Guillermo (coord.) (1990) México: UIA 40

Recepción televisiva: tres aproximaciones y una razón para su estudio.

(Cuadernos de

Comunicación y

Prácticas Sociales) 
Debido a que el corpus de 140 libros de Galindo et al. (2005) clasifica pero no jerarquiza las obras incluidas, se seleccionaron las 148 más frecuentemente citadas en el corpus de Fuentes (incluyendo las que tuvieron 11 o más citas en las tesis) y se hizo de ambos conjuntos una división tripartita de los libros, según el origen de sus autores (extranjeros, iberoamericanos, mexicanos), que se muestra en el cuadro 7.

\begin{tabular}{lcc}
\hline \multicolumn{3}{c}{ CUADRO 7 } \\
LIBROS INCLUIDOS POR GALINDO ET AL. (2005) Y POR \\
FUENTES (EN PROCESO), SEGÚN EL ORIGEN DE SUS AUTORES \\
Origen de los autores & Galindo et al. $(2005)$ & Fuentes (en proceso) \\
\hline Extranjero & $75(53.6 \%)$ & $86(58.1 \%)$ \\
Iberoamericano & $29(20.7 \%)$ & $26(17.6 \%)$ \\
Mexicano & $36(25.7 \%)$ & $36(24.3 \%)$ \\
Totales & $140(100 \%)$ & $148(100 \%)$ \\
\hline
\end{tabular}

Si bien la composición agregada de los dos conjuntos bibliográficos, según el origen de los autores, no presenta diferencias notables, estas aparecen al comparar los títulos incluidos en cada uno. 21 de los 140 textos propuestos por Galindo et al. (2005), no aparecen citados en las tesis: es decir, no forman parte del conjunto de casi diez mil libros referidos al menos una vez en las bibliografías de los trabajos terminales de los posgrados mexicanos, y 83 más aparecen citados en menos de once tesis, por lo que no forman parte del corpus de 148 libros recortado para esta comparación. En consecuencia, solamente 36 obras forman parte de ambas selecciones, una cuarta parte de las elegidas por el GUCOM, lo cual podría poner en duda sus criterios de selección, especialmente si se considera el interés de Galindo por "la construcción de las bases para un programa de investigación y altos estudios en comunicación" (Galindo, 2005: 9), donde "altos estudios" se entiende como sinónimo de posgrado. En el cuadro 8 se exponen los títulos coincidentes, divididos según su origen.

Al comparar los títulos incluidos en el cuadro 8 con los del cuadro 6, salta a la vista la ausencia de la mitad (7 de 14) de los textos empíricamente más citados en las tesis mexicanas (según Fuentes) en la 


\section{CUADRO 8}

LIBROS COINCIDENTES, INCLUIDOS TANTO POR GALINDO ET AL. (2005)

COMO POR FUENTES (EN PROCESO), SEGÚN EL ORIGEN DE SUS AUTORES

Texto [fecha de publicación original] Edición en Frec.en español Fuentes (en proceso)

\begin{tabular}{|c|c|c|}
\hline Autores extranjeros & & \\
\hline $\begin{array}{l}\text { BERLO, D.K. [1960] El proceso de } \\
\text { la comunicación. Introducción a la } \\
\text { teoría y a la práctica }\end{array}$ & $\begin{array}{l}\text { Buenos Aires: El } \\
\text { Ateneo }\end{array}$ & 15 \\
\hline $\begin{array}{l}\text { De FLEUR, M. y S.BALL-ROKEACH } \\
\text { [1966] Teorias de la comunicación } \\
\text { de masas }\end{array}$ & $\begin{array}{l}\text { Barcelona: } \\
\text { Paidós }\end{array}$ & 13 \\
\hline $\begin{array}{l}\text { ECO, U. [1976] Tratado de semiótica } \\
\text { general }\end{array}$ & $\begin{array}{l}\text { Barcelona: } \\
\text { Lumen }\end{array}$ & 21 \\
\hline $\begin{array}{l}\text { ECO, U. [1965] Apocalipticos e } \\
\text { integrados ante la cultura de masas }\end{array}$ & $\begin{array}{l}\text { Barcelona: } \\
\text { Lumen }\end{array}$ & 12 \\
\hline $\begin{array}{l}\text { GOFFMAN, E. [1959] La presentación } \\
\text { de la persona en la vida cotidiana }\end{array}$ & $\begin{array}{l}\text { Buenos Aires: } \\
\text { Amorrortu }\end{array}$ & 12 \\
\hline $\begin{array}{l}\text { HABERMAS, J. [1981] Teoría de la } \\
\text { acción comunicativa ( } 2 \text { volúmenes) }\end{array}$ & Madrid: Taurus & 40 \\
\hline $\begin{array}{l}\text { JENSEN, K.B. y N. JANKOWSKI (eds.) } \\
\text { [1991] Metodologías cualitativas de } \\
\text { investigación en comunicación de } \\
\text { masas }\end{array}$ & Barcelona: Bosch & 20 \\
\hline $\begin{array}{l}\text { KRAUSS, S. y D. DAVIS [1975] } \\
\text { Comunicación masiva, sus efectos en } \\
\text { el comportamiento politico }\end{array}$ & México: Trillas & 11 \\
\hline $\begin{array}{l}\text { MATTELART, A. y M. [1995] Historia } \\
\text { de las teorias de la comunicación }\end{array}$ & $\begin{array}{l}\text { Barcelona: } \\
\text { Paidós }\end{array}$ & 37 \\
\hline $\begin{array}{l}\text { McBRIDE, S. et al. [1980] Un } \\
\text { solo mundo, voces múltiples. } \\
\text { Comunicación e información en } \\
\text { nuestro tiempo }\end{array}$ & $\begin{array}{l}\text { México: FCE/ } \\
\text { UNESCO }\end{array}$ & 14 \\
\hline
\end{tabular}




\begin{tabular}{|c|c|c|}
\hline Texto [fecha de publicación original] & $\begin{array}{l}\text { Edición en } \\
\text { español }\end{array}$ & $\begin{array}{c}\text { Frec. en } \\
\text { Fuentes (en } \\
\text { proceso) }\end{array}$ \\
\hline $\begin{array}{l}\text { McLUHAN, M. [1964] La comprensión } \\
\text { de los medios como extensiones del } \\
\text { hombre }\end{array}$ & México: Diana & 26 \\
\hline $\begin{array}{l}\text { McQUAIL, D. [1987] Introducción a la } \\
\text { teoría de la comunicación de masas }\end{array}$ & $\begin{array}{l}\text { Barcelona: } \\
\text { Paidós }\end{array}$ & 31 \\
\hline $\begin{array}{l}\text { MORLEY, D. [1992] Televisión, } \\
\text { audiencias y estudios culturales }\end{array}$ & $\begin{array}{l}\text { Buenos Aires: } \\
\text { Amorrortu }\end{array}$ & 31 \\
\hline $\begin{array}{l}\text { O’SULLIVAN, T. et al. [1995] } \\
\text { Conceptos clave en comunicación y } \\
\text { estudios culturales }\end{array}$ & $\begin{array}{l}\text { Buenos Aires: } \\
\text { Amorrortu }\end{array}$ & 17 \\
\hline $\begin{array}{l}\text { SILVERSTONE, R. [1994] Televisión y } \\
\text { vida cotidiana }\end{array}$ & $\begin{array}{l}\text { Buenos Aires: } \\
\text { Amorrortu }\end{array}$ & 20 \\
\hline $\begin{array}{l}\text { THOMPSON, J. B. [1990] Ideología } \\
\text { y cultura moderna. Teoría crítica } \\
\text { social en la era de la comunicación } \\
\text { de masas }\end{array}$ & $\begin{array}{l}\text { México: UAM } \\
\text { Xochimilco }\end{array}$ & 79 \\
\hline $\begin{array}{l}\text { WOLF, M. [1985] La investigación de } \\
\text { la comunicación de masas. Crítica y } \\
\text { perspectivas }\end{array}$ & $\begin{array}{l}\text { Buenos Aires: } \\
\text { Paidós }\end{array}$ & 57 \\
\hline $\begin{array}{l}\text { WOLF, M. [1992] Los efectos sociales } \\
\text { de los media }\end{array}$ & $\begin{array}{l}\text { Buenos Aires: } \\
\text { Paidós }\end{array}$ & 13 \\
\hline Autores iberoamericanos & & \\
\hline $\begin{array}{l}\text { CASTELLS, M. [1996] La era de la } \\
\text { información. Economía, sociedady } \\
\text { cultura (3 volúmenes) }\end{array}$ & $\begin{array}{l}\text { México: Siglo } \\
\text { XXI }\end{array}$ & 54 \\
\hline $\begin{array}{l}\text { MORAGAS, M. de [1981] Teorias } \\
\text { de la comunicación de masas. } \\
\text { Investigaciones sobre medios en } \\
\text { América y Europa. }\end{array}$ & $\begin{array}{l}\text { Barcelona: } \\
\text { Gustavo Gili }\end{array}$ & 19 \\
\hline $\begin{array}{l}\text { MORAGAS, M. de [1985] Sociología } \\
\text { de la comunicación de masas ( } 4 \\
\text { volúmenes) }\end{array}$ & $\begin{array}{l}\text { Barcelona: } \\
\text { Gustavo Gili }\end{array}$ & 28 \\
\hline
\end{tabular}




\begin{tabular}{|c|c|c|}
\hline Texto [fecha de publicación original] & $\begin{array}{l}\text { Edición en } \\
\text { español }\end{array}$ & $\begin{array}{l}\text { Frec. en } \\
\text { Fuentes (en } \\
\text { proceso) }\end{array}$ \\
\hline $\begin{array}{l}\text { MARTÍN BARBERO, J. [1987] De } \\
\text { los medios a las mediaciones. } \\
\text { Comunicación, cultura y hegemonía }\end{array}$ & $\begin{array}{l}\text { México: Gustavo } \\
\text { Gili }\end{array}$ & 67 \\
\hline $\begin{array}{l}\text { MARTÍN SERRANO, M. [1986] La } \\
\text { producción social de comunicación }\end{array}$ & Madrid: Alianza & 16 \\
\hline $\begin{array}{l}\text { PASQUALI, A. [1970] Comprender la } \\
\text { comunicación }\end{array}$ & $\begin{array}{l}\text { Caracas: Monte } \\
\text { Ávila }\end{array}$ & 11 \\
\hline $\begin{array}{l}\text { VERÓN, E. [1987] La semiosis social. } \\
\text { Fragmentos de una teoría de la } \\
\text { discursividad }\end{array}$ & $\begin{array}{l}\text { Buenos Aires: } \\
\text { Gedisa }\end{array}$ & 16 \\
\hline Autores mexicanos & & \\
\hline $\begin{array}{l}\text { CHARLES, M. y G. OROZCO (eds.) } \\
\text { [1990] Educación para la recepción }\end{array}$ & México: Trillas & 16 \\
\hline $\begin{array}{l}\text { FERNÁNDEZ CHRISTLIEB, F. [1982] } \\
\text { Los medios de difusión masiva en } \\
\text { México }\end{array}$ & $\begin{array}{l}\text { México: Juan } \\
\text { Pablos }\end{array}$ & 23 \\
\hline $\begin{array}{l}\text { FUENTES N., R. [1998] La emergencia } \\
\text { de un campo académico. Continuidad } \\
\text { utópica y estructuración científica de } \\
\text { la investigación de la comunicación } \\
\text { en México }\end{array}$ & $\begin{array}{l}\text { Guadalajara: } \\
\text { ITESO/ UdeG }\end{array}$ & 15 \\
\hline $\begin{array}{l}\text { GALINDO C., J. (coord.) [1998] } \\
\text { Técnicas de investigación en } \\
\text { sociedad, cultura y comunicación }\end{array}$ & $\begin{array}{l}\text { México: Addison } \\
\text { Wesley Longman }\end{array}$ & 17 \\
\hline $\begin{array}{l}\text { GARCÍA CANCLINI, N. [1990] } \\
\text { Culturas hibridas. Estrategias para } \\
\text { entrar y salir de la modernidad }\end{array}$ & $\begin{array}{l}\text { México: Grijalbo/ } \\
\text { CONACULTA }\end{array}$ & 41 \\
\hline $\begin{array}{l}\text { GÓMEZ MONT, C. [1992] El } \\
\text { desafio de los nuevos medios de } \\
\text { comunicación en México }\end{array}$ & $\begin{array}{l}\text { México: Diana/ } \\
\text { AMIC }\end{array}$ & 13 \\
\hline $\begin{array}{l}\text { GONZÁLEZ, J.A. [1994] Más (+) } \\
\text { cultura(s). Ensayos sobre realidades } \\
\text { plurales }\end{array}$ & $\begin{array}{l}\text { México: } \\
\text { CONACULTA }\end{array}$ & 18 \\
\hline
\end{tabular}




\begin{tabular}{llc} 
Texto [fecha de publicación original] & \multicolumn{1}{c}{$\begin{array}{c}\text { Edición en } \\
\text { español }\end{array}$} & $\begin{array}{c}\text { Frec. en } \\
\text { Fuentes (en } \\
\text { proceso) }\end{array}$ \\
\hline $\begin{array}{l}\text { LOZANO R., J.C. [1996] Teoría e } \\
\text { investigación de la comunicación de } \\
\text { masas }\end{array}$ & $\begin{array}{l}\text { México: } \\
\text { Alhambra }\end{array}$ & 44 \\
\hline $\begin{array}{l}\text { REGUILLO C., R. [1991] En la calle } \\
\text { otra vez. Las bandas: identidad }\end{array}$ & Guadalajara: & 13 \\
urbana y usos de la comunicación & ITESO & \\
\hline $\begin{array}{l}\text { SÁNCHEZ RUIZ, E.E. [1992] Medios } \\
\text { de difusión y sociedad. Notas críticas }\end{array}$ & Guadalajara: & 27 \\
y metodológicas & UdeG & 14 \\
\hline $\begin{array}{l}\text { TREJO D., R. (coord.) [1985] Televisa, } \\
\text { el quinto poder }\end{array}$ & $\begin{array}{l}\text { México: Claves } \\
\text { Latinoamericanas }\end{array}$ & \\
\hline
\end{tabular}

propuesta del GUCOM. Quizá estas obras (seis de autores extranjeros y un mexicano) no tomadas en cuenta por Galindo et al. (2005) podrían también ser consideradas, pues sin duda aportan "sustento a una ciencia posible" y están ya "presentes en el campo académico", además, por supuesto, de que se dispone de ellas en español (Galindo, 2005: 19).

Entre los libros excluidos figura el "manual" de investigación más frecuentemente citado en las tesis (Taylor y Bogdan), seguramente porque Rizo (2006) no lo consideró referido a las "teorías de la comunicación". Pero el dato más fuerte de esta comparación tiene que ver con el hecho de que las obras más citadas en las tesis y no incluidas por el GUCOM, son en su mayoría ( 5 de 7) libros de autores que están entre los diez más citados en las tesis (sumando las referencias de sus diferentes obras): Guillermo Orozco (361 citas en total), Pierre Bourdieu (360), Anthony Giddens (168) y John B. Thompson (145). Berger y Luckmann (68 y 71) y Clifford Geertz (64), aunque no están entre los diez autores más citados, sí escribieron sendas obras (La construcción social de la realidad y La interpretación de las culturas) muy influyentes en los estudios sociales y de la comunicación en México y más allá11.

11 La obra de Berger y Luckmann, así como el Tratado de semiótica general de Eco y otros libros muy citados en estudios de la comunicación (de Aus- 
Estas propuestas, sin embargo, como todas las demás de su género, aportan al campo académico insumos reflexivos que pueden incorporarse (o no), de diversas maneras dependientes de las perspectivas de los agentes, de las diversas "comunidades" de practicantes, a interpretaciones y acciones consecuentes, cuyos resultados (por ejemplo, la "adopción" de ciertos marcos teórico-metodológicos o la lectura de ciertos textos, o la escritura de artículos como este), vuelven a quedar a disposición de quien los discuta y aproveche, y también como representaciones que "objetivan", de determinadas maneras, la construcción constante del campo.

\section{LOS LIBROS CITADOS Y LOS DIVERSOS “ENCLAVES” DEL CAMPO EN MÉXICO}

Para concluir este trabajo, centrado en la compleja relación entre programas educativos y fuentes bibliográficas, se presenta un avance de los análisis en proceso sobre la información sistematizada acerca de las referencias citadas en las tesis de posgrado en comunicación en México, según el proyecto ya mencionado (Fuentes, 2004). En particular, se exponen las diferencias encontradas entre programas de maestría, en cuanto a los libros más citados en las tesis presentadas en cada uno de ellos; es decir, se explora el eje institucional de diferenciación "intra-campo".

Como se había ya señalado, se trabaja la información proveniente de cinco programas de maestría en comunicación, aquellos acreditados por el Padrón Nacional de Posgrados de CONACyT o, en otras palabras, los que han alcanzado un cierto grado de consolidación académica. La antigüedad de los programas es diversa, así como las condiciones, formas de organización y "tradiciones académicas" en las se insertan. Dos se ubican en universidades públicas (UNAM y UdeG) y tres en privadas (UIA, ITESO, ITESM). Dos tienen su sede en la ciudad de México, dos en

tin, Barthes, Benveniste, Chomsky, Foucault, Gombrich, Jakobson, LéviStrauss, Propp, Saussure, Searle, Wittgenstein, entre otros) forman parte de las cincuenta obras más citadas entre 1976 y 1983 en el Arts and Humanities Citation Index, según el "padre fundador" de la bibliometría, Eugene Garfield (1987). 
Guadalajara y una en Monterrey. Como era de suponerse, el número de tesis presentadas también difiere. Por ello la exploración de los respectivos "patrones de citación" en las tesis puede interpretarse en relación con otras diferencias. En el cuadro 9 se presentan los datos básicos de la comparación.

\begin{tabular}{|c|c|c|c|c|c|c|}
\hline \multicolumn{7}{|c|}{$\begin{array}{c}\text { CUADRO } 9 \\
\text { TESIS DE MAESTRÍA EN COMUNICACIÓN PRESENTADAS EN } \\
\text { MÉXICO ENTRE } 1996 \text { Y 2005, POR UNIVERSIDAD (FUENTES, EN PROCESO) }\end{array}$} \\
\hline 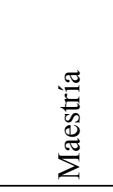 & $\stackrel{\substack{\infty \\
\infty}}{\oplus}$ & 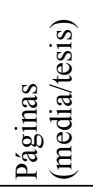 & 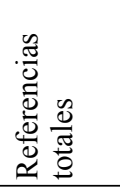 & 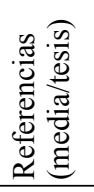 & 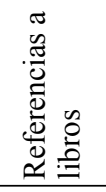 & 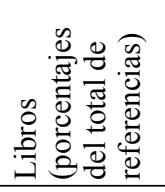 \\
\hline UNAM & 112 & 199.8 & 10,461 & 93.4 & 5,896 & 56.4 \\
\hline UdeG & 41 & 198.1 & 3,359 & 81.9 & 1,781 & 52.9 \\
\hline ITESO & 30 & 171.1 & 2,464 & 82.1 & 1,197 & 48.5 \\
\hline UIA & 84 & 206.9 & 6,610 & 78.7 & 2,935 & 44.3 \\
\hline ITESM & 89 & 102.5 & 3,578 & 40.2 & 1,220 & 34.2 \\
\hline Totales & 356 & 172.6 & 26,472 & 74.3 & 13,029 & 49.3 \\
\hline
\end{tabular}

Algunas diferencias notables quedan en evidencia en el cuadro 9, como la desproporción entre instituciones en cuanto al número de tesis, explicable en principio porque las maestrías del ITESO y la UdeG comenzaron a operar apenas en 1998, o las grandes diferencias en cuanto al número promedio de páginas o la media de referencias de las tesis, donde las presentadas en el ITESM quedan muy por debajo del promedio. Pero quizá para los propósitos de este artículo, la característica diferencial más interesante sea la proporción de las referencias a libros con respecto a las referencias totales manifiestas en las tesis. El caso extremo en este aspecto, otra vez el ITESM, "compensa" el hecho de citar el menor porcentaje de libros, con el mayor en cuanto a citas de capítulos, artículos y tesis en sus propias tesis, que siguen un "estilo" de investigación más empirista y "situado" que las de las demás universidades. 
Hay, por supuesto, también diferencias entre instituciones con respecto a los temas y enfoques de las tesis, pero ese análisis se presentará en otra ocasión, debido sobre todo a la complejidad del desarrollo de las categorías de análisis. Aunque está relacionado con este "recorte", se presenta por ahora, en el cuadro 10, la bibliografía jerarquizada por institución, es decir, la lista de libros más citados en cada uno de los cinco programas de maestría, que al compararse con el "agregado nacional" del cuadro 6, puede dar una idea más precisa sobre las referencias comunes en el campo académico, y las que indican divergencias "locales" $\mathrm{o}$ institucionales.

Tomando como base las 12 ( \pm 1 , por los “empates") obras más citadas por universidad, queda de manifiesto la presencia de todos los textos incluidos en el cuadro 6, donde se agregan nacionalmente las frecuencias (la única excepción es Habermas, además de cuatro textos que aparecen en una sola institución), de donde puede desprenderse que los nueve textos restantes 12 forman la "plataforma central" de la bibliografía fundamental para los "altos estudios" de comunicación en México. Pero hay otros 30 libros que aparecen entre los más citados en una sola institución, entre ellos, no casualmente, algunos publicados por profesores del propio programa (González Reyna en la UNAM; Orozco y Sánchez Ruiz en la UdeG; Orozco y Fuentes en el ITESO; Lozano y Maza-Cervantes en el ITESM), o manuales no incluidos por Rizo (2006) en su revisión (como el de Hernández Sampieri et al. y el de Taylor y Bogdan, citados cada uno en dos universidades, o el de Severin y Tankard, en inglés, analizado por Anderson, y muy utilizado en el ITESM).

La lista de libros del cuadro 10 nos permite también deducir que, además de libros fundamentales de teoría y metodología en ciencias sociales, la bibliografía empleada en las maestrías estudiadas incluye

12 Es decir, Ideología y cultura moderna de Thompson (4 instituciones), De los medios a las mediaciones de Martín Barbero (4), La era de la información de Castells (3), La construcción social de la realidad de Berger y Luckmann (2), Los media y la modernidad de Thompson (2), La constitución de la sociedad de Giddens (2) y Sociología y cultura de Bourdieu (2), así como los manuales de Wolf (2) y de Taylor y Bogdan (2). 


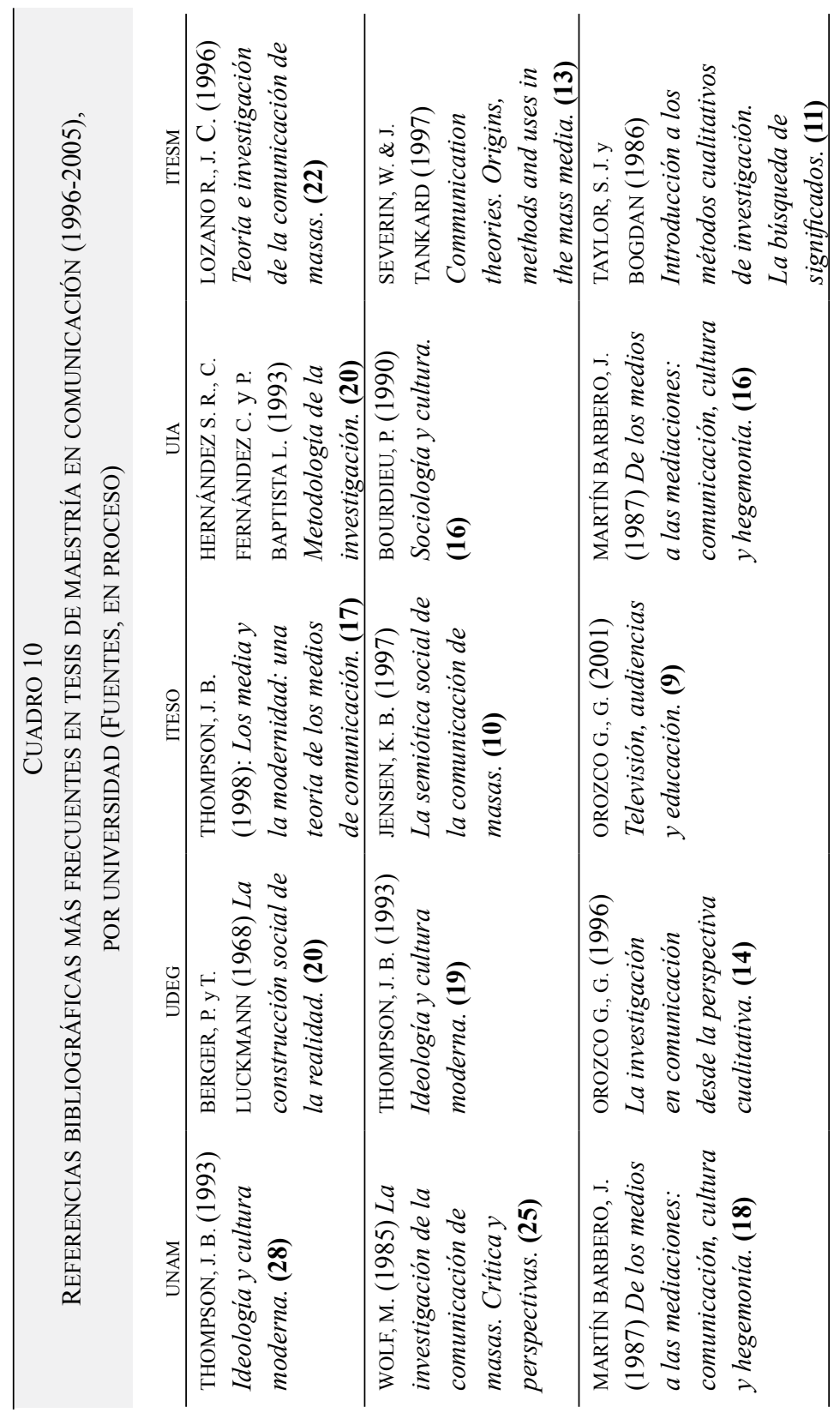




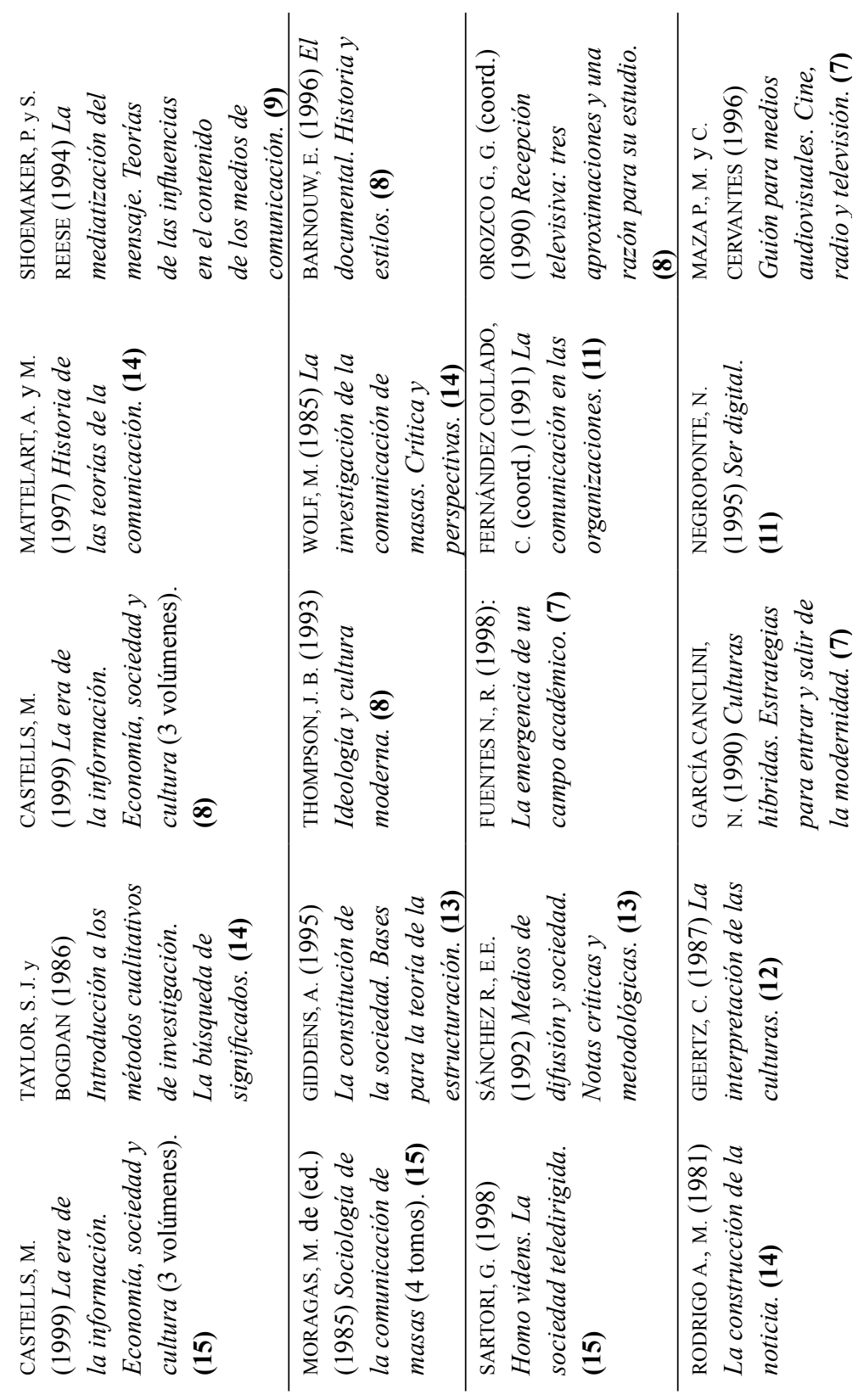




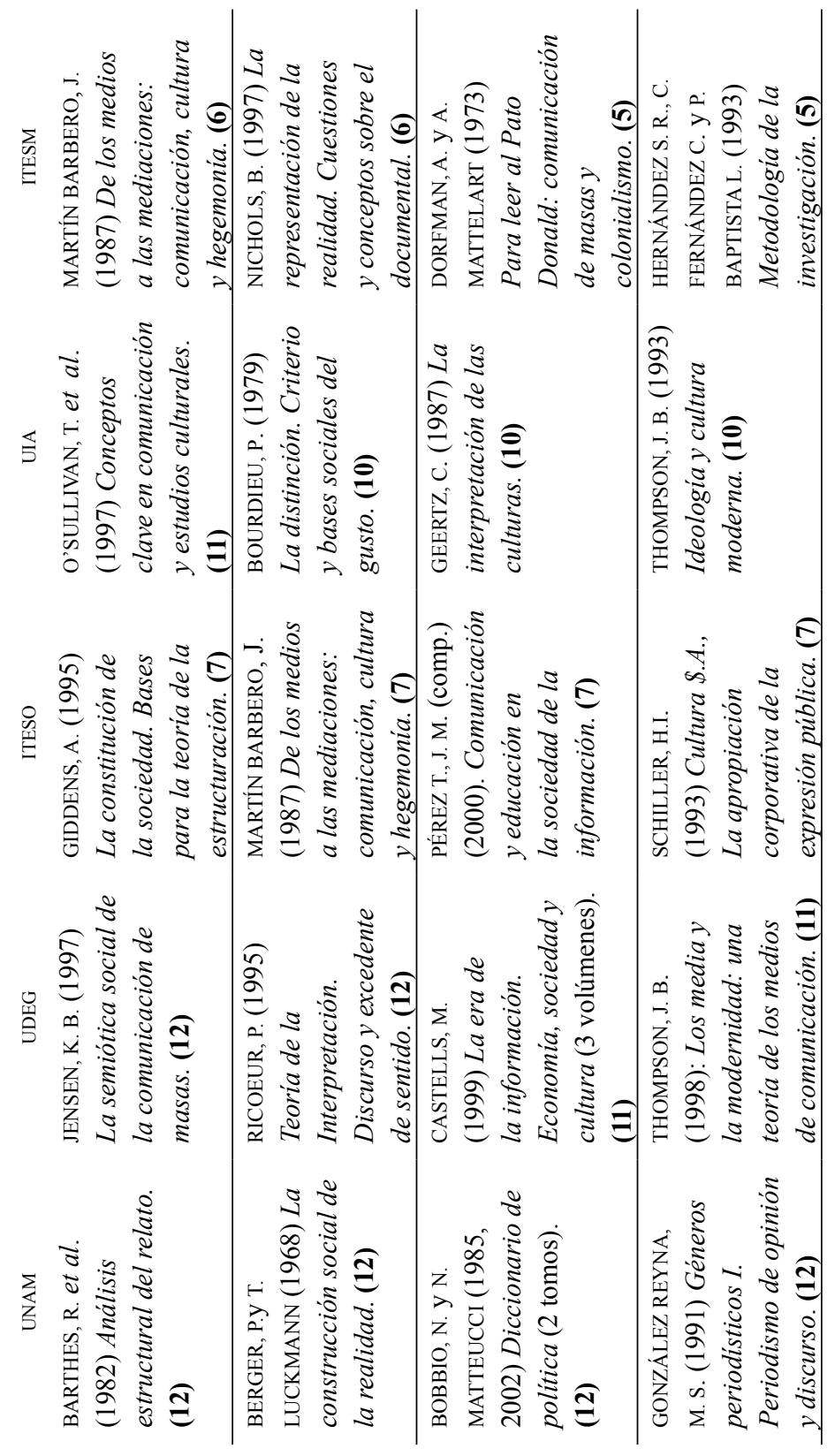




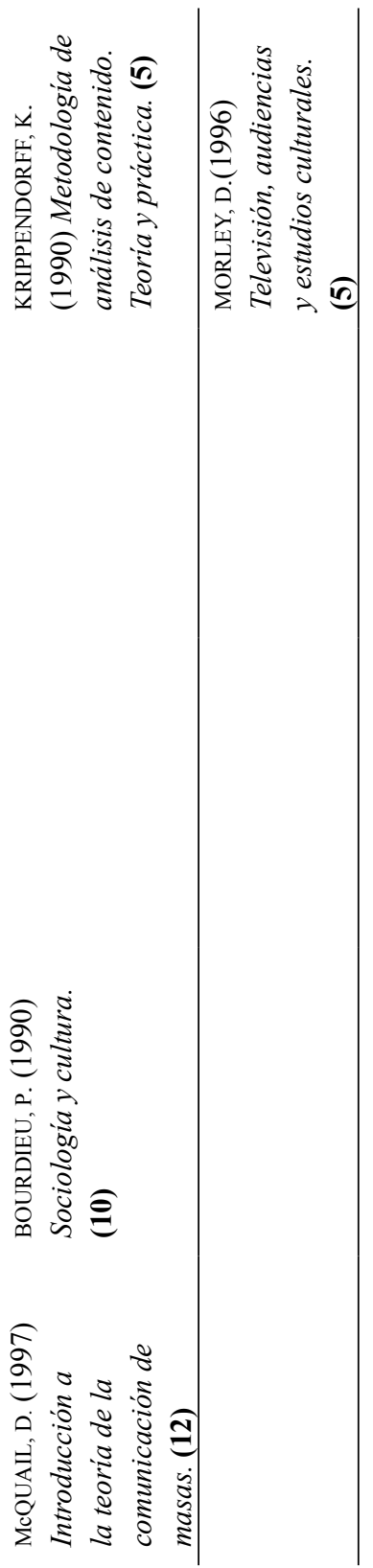


también una alta proporción de manuales de investigación (social en general, de la comunicación, y de algunas especialidades), algunos más "didácticos" que otros, y muy pocos casos de estudios monográficos sobre algún objeto particular de investigación. De ahí pueden asociarse otros datos (no consignados aquí), para elaborar hipótesis más finas sobre los usos bibliográficos que distinguen a las maestrías entre sí. Pero un último dato del cuadro 10 sí puede resaltarse desde ahora: el origen de los autores de los textos más citados en cada universidad: en la UNAM hay 7 extranjeros, 4 iberoamericanos y 1 mexicano; en la UdeG, 9, 1 y 2; en el ITESO, 5, 3 y 3; en la UIA, 8, 1 y 2, y en el ITESM, 7, 2 y 4. Pareciera que en el ITESO y en el ITESM hay una "preferencia" por textos originalmente escritos en español (por mexicanos o iberoamericanos) y en las otras universidades por las traducciones, pero no es así. Para despejar esta duda, en el cuadro 11 se presentan las proporciones de libros referidos en total en las tesis de maestría de cada institución. Aunque el ITESO mantiene la proporción más equilibrada entre textos de origen "extranjero" y mexicanos/iberoamericanos, y el porcentaje más alto de citas a iberoamericanos, el mayor porcentaje de citas a "extranjeros" está, por mucho, en el ITESM, y el mayor porcentaje de citas a mexicanos, en la UNAM.

Es probable que el dato más interesante, con respecto a la relación entre programas educativos y fuentes bibliográficas, entre los presentados hasta ahora, sea el indicado en la última columna del cuadro 11: el porcentaje de referencias (más que una cuarta parte del total) que provienen de libros escritos por mexicanos, y que sumadas a las originadas en autores iberoamericanos, representa cerca de la mitad de las fuentes bibliográficas referidas. Aunque esta distribución indudablemente tiene que relacionarse con las temáticas de las tesis para identificar las asociaciones de la bibliografía con líneas de investigación, donde seguramente habrá otras diferencias entre instituciones, puede elaborarse una hipótesis tentativa en cuanto a que las referencias bibliográficas de las tesis de maestría mexicanas tienden a equilibrarse en cuatro grupos más o menos equivalentes: las que "conectan" con la producción angloamericana, con la europea en idiomas distintos del inglés, con la iberoamericana y con la mexicana, de manera que, quizás, habría un balance adecuado en cuanto a la recurrencia a las fuentes y tradiciones 


\section{CUADRO 11}

REFERENCIAS A LIBROS, SEGÚN ORÍGENES DE SUS AUTORES,

EN TESIS DE MAESTRÍA EN COMUNICACIÓN PRESENTADAS EN MÉXICO ENTRE 1996 Y 2005, POR UNIVERSIDAD (FUENTES, EN PROCESO)

\begin{tabular}{|c|c|c|c|c|c|}
\hline 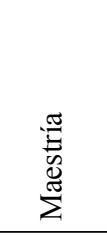 & $\stackrel{\infty}{\infty}$ & 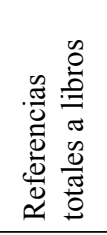 & 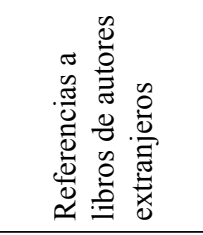 & 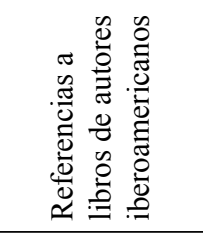 & 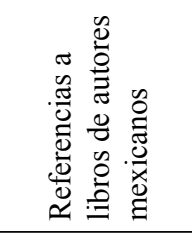 \\
\hline UNAM & 112 & 5,896 & $3096(52.5 \%)$ & $1075(18.2 \%)$ & $1725(29.3 \%)$ \\
\hline UdeG & 41 & 1,781 & $1015(57.0 \%)$ & $268(15.0 \%)$ & $498(28.0 \%)$ \\
\hline ITESO & 30 & 1,197 & $608(50.8 \%)$ & $264(22.1 \%)$ & $325(27.1 \%)$ \\
\hline UIA & 84 & 2,935 & $1580(53.8 \%)$ & $506(17.2 \%)$ & $849(29.0 \%)$ \\
\hline ITESM & 89 & 1,220 & $781(64.0 \%)$ & $185(15.2 \%)$ & $254(20.8 \%)$ \\
\hline Totales & 356 & 13,029 & $7,080(54.3 \%)$ & 2,298 (17.6\%) & $3,651(28.1 \%)$ \\
\hline
\end{tabular}

de investigación de la comunicación propias del área hispanohablante, y las de más amplio origen internacional.

Queda muy claro, sin embargo, que el desarrollo de la investigación de la comunicación en México, según su proyección de tendencias en las tesis de maestría, no tiende hacia una convergencia conceptual o a una consolidación disciplinaria, sino hacia lo contrario: a una creciente diversificación de marcos de fundamentación y a una especialización temática que se basa en marcos transdisciplinarios de las ciencias sociales y las humanidades. Pero sin duda, deseablemente con el apoyo creciente en datos empíricos interpretados, el debate, tanto descriptivo como normativo sobre el carácter disciplinario de los estudios de la comunicación, tendrá que seguir.

\section{Bibliografía}

ANDERSON, James A. (1996) Communication theory. Epistemological foundations. New York and London: The Guilford Press.

BOURDIEU, Pierre (1988) Homo academicus. California: Stanford University Press.

- (2000): Los usos sociales de la ciencia. Buenos Aires: Nueva Visión. 
BRYANT, Jennings and Dorina Miron (2004) "Theory and research in mass communication", Journal of Communication, vol. 54, núm. 4.

FUENTES NAVARRO, Raúl (2004) "La constitución científica del campo académico de la comunicación en México y en Brasil: análisis comparativo", protocolo de investigación presentado al Comité de Ciencias Sociales del Fondo de Ciencia Básica del Consejo Nacional de Ciencia y Tecnología.

GALINDO CÁCERES, Jesús (2005) "La construcción de las bases para un programa de investigación y altos estudios en comunicación", en Galindo, Karam y Rizo, Cien libros hacia una comunicología posible. Ensayos, reseñas y sistemas de información, México: Universidad Autónoma de la Ciudad de México.

- y Marta Rizo García (2005) "Bibliografía y comunicología posible. Trayectoria, diagnóstico y configuración de opciones, libros y autores en la bibliografía en español y en idioma distinto al español", en Galindo, Karam y Rizo, Cien libros hacia una comunicología posible. Ensayos, reseñas y sistemas de información, México: Universidad Autónoma de la Ciudad de México.

- Tanius Karam Cárdenas y Marta Rizo García (2005): Cien libros hacia una comunicología posible. Ensayos, reseñas y sistemas de información, México: Universidad Autónoma de la Ciudad de México.

GARFIELD, Eugene (1987) "A different sort of Great-Books List: the 50 twentieth-century works most cited in the Arts \& Humanities Citation Index, 1976-1983”, Current Contents núm. 16.

KATZ, Elihu, John Durham Peters, Tamar Liebes and Avril Orloff (eds.) (2003) Canonic texts in media research are there any? Should there be? How about these? Cambridge UK: Polity Press.

KUHN, Thomas S. (1970) The structure of scientific revolutions. (2nd edition), Chicago: The University of Chicago Press.

MOLINER, María (1992): Diccionario de uso del español, Madrid: Gredos.

POOLEY, Jefferson D. (2005) "Canonic texts in media research... A Review”, Journal of Communication, vol. 55, núm. 1.

RIZO GARCÍA, Marta (2006) "La teoría en el campo académico de la comunicación. Análisis de manuales de teoría de la comunicación 
desde la propuesta de la comunicología posible", en Martell, Rizo y Vega (coords.), Políticas de comunicación social y desarrollo regional en América Latina, volumen II, México: Universidad Autónoma de la Ciudad de México/ Asociación Mexicana de Investigadores de la Comunicación.

SHEPHERD, Gregory J., Jeffrey St. John y Ted Striphas (eds.) (2006) Communication as ... perspectives on theory, Thousand Oaks, CA: Sage. 